\title{
The Role of the Building Consultant
}

Institutions are coming increasingly to recognize the value of retaining outside library competence in a consultative capacity during the planning and construction of new library buildings. This paper explains the role of such consultants during five stages of building development: (1) the initial program; (2) program development; (3) early design; (4) final design; and (5) working drawings and specifications.

\section{$\mathrm{T}$}

HE STORY IS TOLD of the woodpecker who became bored with the routines of his life and embarked on a cross-country trip to a distant point and a change of scene. After flying many miles, the bird was forced by an approaching storm to land in a tall oak. True to the instincts of his kind, he took a tentative tap at the tree just as a bolt of lightning split the trunk full-length. After recovering his composure, the bird surveyed the damage and was awed by what he saw. "Isn't it amazing," he said to himself, "what an ordinary woodpecker can accomplish once he gets away from home."

This story has a message for both building consultants and the colleges and universities that employ them. For the institutions involved, it demonstrates that proper timing in the matter of involving a consultant is essential if ordinary efforts are to produce exceptional results. For the consultant, the story warns that artificially induced delusions of grandeur tend to push the limits of confidence beyond the realities of competence.

But these two observations are by no

Mr. Haas is Director of Libraries in the University of Pennsylvania. This paper was copyrighted in 1968 by the Society for College and University Planning and is reprinted from its Quarterly by permission. means the only ones that might be made concerning consultants in the programming and design of academic buildings. The comments that follow explore the relationship between the consultant and the employing institution and suggest a few guidelines for making that relationship fully effective. While library planning experience provides the basis for this decision, the points made are likely to be generally pertinent to other areas as well.

At the outset, it should be noted that the role of the consultant changes with each assignment. The degree of involvement is governed by institutional needs and policy, and since these are bound to vary, it follows that there is no fixed pattern governing the relationship between a college or university and its consultant. In an effort to identify most of the areas in which a consultant might participate, five distinct stages in the planning process are considered and the nature of the contributions a consultant might be expected to make in each phase is suggested.

\section{The Initial Program}

The importance of timing has already been noted. In general, the earlier a consultant is involved, the better will be the results. The fundamental thinking that serves as a basis for the initial pro- 
gram document on a new library building should reflect conclusions of those responsible for long-range campus planning, senior institutional administrators, and the library. The product of this planning phase might be a simple statement of need (for example, we need a new one million volume library with two thousand seats) arrived at on the evidence of a few obvious facts. At the other extreme, the initial program might be a complex document outlining the institution's projected educational activities and pedagogical techniques to be employed, along with a detailed description of the library operations projected to support those activities.

In established colleges and universities, a consultant is often not involved in the conversation and studies that lead to the recommendations incorporated in the initial program, simply because this work is a part of continuing institutional planning activity. For this very reason, it is important that the consultant review the conclusions to verify that they are in fact as valid when viewed from the outside as they seem to those within. Because the prescription for action and the supporting philosophy of this initial program are in a real sense the foundation from which the detailed program and ultimately the building itself rises, their importance should not be underestimated. The consultant needs to satisfy himself that the conclusions incorporate the best of all possible options, or at least that all possible options were considered. This requires an intensive effort on the part of the consultant to gain historical perspective as well as to understand the future objectives of the institution. In large universities especially, the consultant has an obligation to verify that any projected building reflects the existence of and is consistent with a longrange program for the development of library service. More and more, it is important to assess regional needs, as distinct from strictly internal needs, in pro- gramming and planning library facilities, simply because many aspects of library and information services are by their very nature best viewed regionally rather than parochially.

While the role of the consultant relative to the initial program is most often that of a reviewer, there are many instances in which he is in fact a participant in, and at times even primarily responsible for, program development. In the case of new colleges, and colleges undergoing dramatic change, a library consultant often finds himself the most experienced person in the planning group and heavily involved in policy formulation. It is critically important in such cases that the consultant avoid being drawn into the decision-making process; this is not properly his role. He must concentrate instead on providing facts and establishing options for those who are responsible. In these circumstances especially, the consultant needs to serve in a kind of educational capacity to provide the institutional participants with pertinent facts and examples of alternatives, as well as an understanding of the implications of different courses of action.

Whether reviewing initial program recommendations made prior to his involvement or participating in the basic planning process, the objective is the same-to assure that the basis for action is sound when viewed in the light of both educational objectives and library management. In effect, an acceptable initial program for a library building is evidence of a proper and realistic institutional commitment to library support.

\section{Program Development}

If the initial program is the place for formulation of broad elements of basic policy, the process of program development and refinement is one requiring meticulous attention to an infinite number of details. If the breadth and depth of the consultant's wisdom is tested in 
the first case, his technical knowledge gained from practical building experience is of paramount importance here. In many instances, the detailed program is developed in the institution, with the consultant providing substantial assistance at all stages of the work. Often, the architect for a building is engaged before the program is completed, opening the way for participation by three parties (institutional representatives, architects, and the consultant) in final program formulation. Inclusion of the architects as a new voice in the final stages of program development can stimulate the planners to refine carefully and evaluate the elements of the program and often can promote inclusion of information of importance to the architect that would otherwise be omitted. The architects, by their early participation, come to comprehend more quickly the nature of their assignment. The consultant can often play an important role in the early stages of the dialogue between architects and the institutional planning team by retaining his "third party" isolation with the purpose of seeing to it that "architectural considerations" do not begin to dominate educational objectives before the program itself is finally developed.

The consultant needs to verify that terms used in the program are defined with precision; that standards used in relating specified capacities (for studies, book storage, staff space, etc.) to actual areas are valid; that all buildings and operating functions are enumerated and their relationships described; that anticipated traffic volumes and patterns are established; that qualitative requirements for building components as well as for environmental elements are clearly established; that such considerations as ease of maintenance and housekeeping are precisely treated; and, where appropriate, that provisions are made for building expansion. In the case of specialized buildings like libraries, a wide range of distinctive equipment must of- ten be included as part of the program, and the consultant's knowledge of many installations is often a valuable resource in this aspect of program formulation.

From the above, it is evident that the role of a consultant in the program development stage has several aspects. $\mathrm{He}$ is a source of up-to-date facts; he can help both his institutional employers and the architects, if they are involved, to learn about alternate solutions by directing them to existing buildings or written material that bear on the problem at hand; and he can often help maintain effective communication among the parties involved, both within the institution and between the institution and the architectural firm.

\section{Early Design}

Program refinement and preliminary design work often overlap in time. In a sense, the early design phase is not unlike the initial period of program preparation, in that one ends in the formulation of the governing educational and operating philosophy and the other culminates in the form of the architectural solution. With this phase, principal responsibility shifts from the institutional planners to the architect. The consultant's role also changes. Given reasonable success by the architect in arriving quite quickly at a solution acceptable to the client, the consultant might be involved only to the extent of verifying for the college or university concerned that the proposed design is compatible with program specifications, and at the same time provides the flexibility and the versatility required to meet the unknown needs of the future.

Generally, it is unwise for the consultant to assume any more than a proportionate share of the responsibility for judging design suggestions from the point of view of aesthetics. It is equally unwise in most cases for the consultant to prepare anything more than schematic layouts of major spaces because he runs 
the risk of dampening architectural imagination and thus producing less than optimal solutions to the problems involved. Architects are not normally interested in plans from consultants' desks.

There are times, however, when an architect has difficulty in finding a building form that provides a space configuration consistent with program requirements and institutional criteria. In such situations, the institution can, and often does, turn to its consultant for advice on how to resolve the problem. It is here especially that a consultant's experience and demonstrated ability are of prime importance, for finding and promoting acceptance for the right course of action often hinges on his statesmanship as well as his architectural instincts.

\section{Final Design}

Assuming the consultant has done his work well in previous stages of the project, his role towards the end of the period of final design is to verify for his employer that the design reflects the general objectives as well as the details of the program.

The review process, whether done at one time or in phases over an extended period, is best carried out in close consultation with the responsible people. It is meticulous work, and often difficult. Give and take on all sides is required, since graphic interpretation of prose specifications is as much an art as it is a science. Further, the "art" in architecture and the requirements of the structural approach chosen both carry their own catalog of restraints that must be comfortable with program requirements, but not obviously subservient to them. In brief, the consultant must help the institution verify that the design in fact reflects the program, even though at times the form of the recommended architectural solution might be something unpredicted and perhaps even unpredictable.

\section{Working Drawings AND SPECIFICATIONS}

In most cases, the consultant is no longer involved once this phase of a project is reached. On occasion, however, he is asked to review specific details to verify that certain program elements have been properly incorporated. Examples include specifications and installation details for technical equipment, as well as those items that indicate proper attention has been paid program admonitions for ease of maintenance and the quality of staff and user environment (for example, the characteristics of window glass specified, security provisions, signs and directional aids, etc.).

These notes suggest the possible range of the consultant's role. Ideally, he adds to the talent devoted to a project. $\mathrm{He}$ is a balance wheel working to resolve divergent views represented within the institution employing him, not by seeking compromise solutions, but by helping establish which is the best solution and developing support for it. $\mathrm{He}$ is a source of facts in his own special area of expertise, but not an oracle either in or outside of that field. Most important, perhaps, he is a kind of mirror helping college and university planners see their institution in a somewhat different light, amplified and focused specifically on the problem at hand. The consultant does not make decisions, but he can help, and at times force, the decision-making process. 